\title{
Coincident Spiking Activity Induces Long-Term Changes in Inhibition of Neocortical Pyramidal Cells
}

\author{
Carl D. Holmgren and Yuri Zilberter \\ Karolinska Institute, Department of Neuroscience, Division of Neuroanatomy and Brain Development, S-17177 \\ Stockholm, Sweden
}

In pyramidal cells, induction of long-term potentiation (LTP) and long-term depression (LTD) of excitatory synaptic transmission by coincidence of presynaptic and postsynaptic activity is considered relevant to learning processes in vivo. Here we show that temporally correlated spiking activity of a pyramidal cell and an inhibiting interneuron may cause LTD or LTP of unitary IPSPs. Polarity of change in synaptic efficacy depends on timing between $\mathrm{Ca}^{2+}$ influx induced by a backpropagating train of action potentials (APs) in pyramidal cell dendrites (10 APs, 50 $\mathrm{Hz}$ ) and subsequent activation of inhibitory synapses. LTD of IPSPs was induced by synaptic activation in the vicinity of the

Backpropagating action potentials (APs) in dendrites of pyramidal cells in neocortex and hippocampus evoke a transient increase in the dendritic $\left[\mathrm{Ca}^{2+}\right]_{\mathrm{i}}$ (Schiller et al., 1995; Magee and Johnston, 1997; Isomura et al., 1999; Kaiser et al., 2001), providing a general associative signal for Hebbian plasticity in active synapses (Magee and Johnston, 1997; Markram et al., 1997a). Coincidence of backpropagating APs with synaptic activity may induce either long-term potentiation (LTP) or long-term depression (LTD) in excitatory synapses depending on a precise temporal order of APs and EPSPs in the millisecond range (Magee and Johnston, 1997; Markram et al., 1997a; Bi and Poo, 1998; Debanne et al., 1998; Egger et al., 1999). It is possible that such temporal patterns of presynaptic and postsynaptic neuron spiking activity exist in vivo during learning episodes and can induce long-term plasticity in active synaptic contacts (Buzsaki et al., 1996; Thomas et al., 1998; King et al., 1999; Paulsen and Sejnowski, 2000).

Excitability of pyramidal cells is effectively controlled by inhibitory interneurons, which can modulate the timing of a spike generation (Miles et al., 1996; Freund and Gulyas, 1997; Thomas et al., 1998; King et al., 1999; Larkum et al., 1999; Zilberter, 2000). Despite the importance of inhibitory transmission in the regulation of pyramidal cell firing, there is a lack of information, to our knowledge, on long-term synaptic plasticity in inhibitory connections resulting from a temporally correlated spiking of a pyramidal cell and an interneuron.

Received May 7, 2001; revised July 10, 2001; accepted July 27, 2001.

This study was supported by Swedish Medicine Research Council Grant 2001/Z0710 and a grant from the Wallenberg Foundation. We thank Drs. N. Burnashev, G. Innocenti, S. Grillner, and A. Marty for critically reading this manuscript. We also thank Dr. G. Innocenti for financial support of this work by his Grant 12594 from the Swedish Medicine Research Council.

Correspondence should be addressed to Dr. Yuri Zilberter, Karolinska Institute, Department of Neuroscience, Division of Neuroanatomy and Brain Development, Retzius väg 8, B2-2, S 17177 Stockholm, Sweden. E-mail: yuri.zilberter@neuro.ki.se. Copyright (C) 2001 Society for Neuroscience $0270-6474 / 01 / 218270-08 \$ 15.00 / 0$
AP train $(<300$ msec relative to the beginning of the train), whereas LTP of IPSPs was initiated with more remote synaptic activation ( $>400$ msec relative to the beginning of the AP train). Solely AP trains induced neither LTP nor LTD. Both LTP and LTD were prevented by $5 \mathrm{~mm}$ BAPTA loaded into pyramidal cells. LTD was prevented by $5 \mathrm{~mm}$ EGTA, whereas EGTA failed to affect LTP. Synaptic plasticity was not dependent on activation of $\mathrm{GABA}_{\mathrm{B}}$ receptors. It was also not affected by the antagonists of vesicular exocytosis, botulinum toxin D, and GDP- $\beta$-S.

Key words: neocortex; interneuron; pyramidal cell; LTP; LTD; coincident detection

In the neocortex, pyramidal cell-interneuron pairs are frequently reciprocally connected (Buhl et al., 1997; Reyes et al., 1998; Zilberter et al., 1999; Zilberter, 2000), creating elementary neuronal microcircuits. In these microcircuits, potentiation (or depression) of the excitatory inputs onto a pyramidal cell may cause a backward increase (or decrease) of inhibition of the pyramidal cell by an interneuron. In a previous study (Zilberter, 2000), it was reported that trains of backpropagating dendritic APs in L2/3 pyramidal cells of the rat neocortex resulted in a short-term synaptic depression of inhibitory transmission induced by the $\mathrm{Ca}^{2+}$-dependent dendritic release of a retrograde messenger. Meanwhile, a long-lasting potentiation of IPSPs was often observed after the AP train conditioning in pyramidal neurons (Zilberter, 2000). Results of the present study demonstrate that either LTD or LTP of inhibitory transmission may be induced depending on the time interval between backpropagating APs in pyramidal cell dendrites and activation of inhibitory synapses.

\section{MATERIALS AND METHODS}

Cortical slices (300 $\mu \mathrm{m}$ thick) were prepared from the brain of 14- to 16-d-old Sprague Dawley rats as described previously (Markram et al., 1997b). Simultaneous dual whole-cell recordings were made in pyramidal cells synaptically connected to fast spiking nonaccommodating (FSN) interneurons (Zilberter, 2000). FSN neurons and pyramidal cells in layer $2 / 3$ were identified by infrared-differential interference contrast video microscopy and subsequent measurements of neuron firing properties. The extracellular solution contained (in $\mathrm{mm}$ ): $125 \mathrm{NaCl}, 2.5 \mathrm{KCl}, 25$ glucose, $25 \mathrm{NaCO}_{3}, 1.25 \mathrm{Na}_{2} \mathrm{PO}_{4}, 2 \mathrm{CaCl}_{2}$, and $1 \mathrm{MgCl}_{2}$. All experiments were performed at $32^{\circ} \mathrm{C}$ in oxygenated extracellular solution. The pipette solution contained (in mM): 100 (or 115) K-gluconate, $20 \mathrm{KCl}, 4$ ATP-Mg, 10 Na-phosphocreatine, 0.3 GTP, and 10 HEPES, pH 7.3 (310 $\mathrm{mOsm} / \mathrm{l})$.

Electrical signals were recorded with Axoclamp 2B and Axopatch 200B amplifiers (Axon Instruments, Foster City, CA), digitized at $20 \mathrm{kHz}$ by an analog-to-digital converter (ITC-18; InstruTech, Great Neck, NY) controlled by a program (Pulse; Heka Elektronik, Lambrecht, Germany) and analyzed off-line using commercial software (IGOR Pro; WaveMetrics Inc., Lake Oswego, OR) with custom-written routines. Patch pipettes had a resistance of 3-4 M $\Omega$. Input resistance to the postsynaptic (pyra- 
A
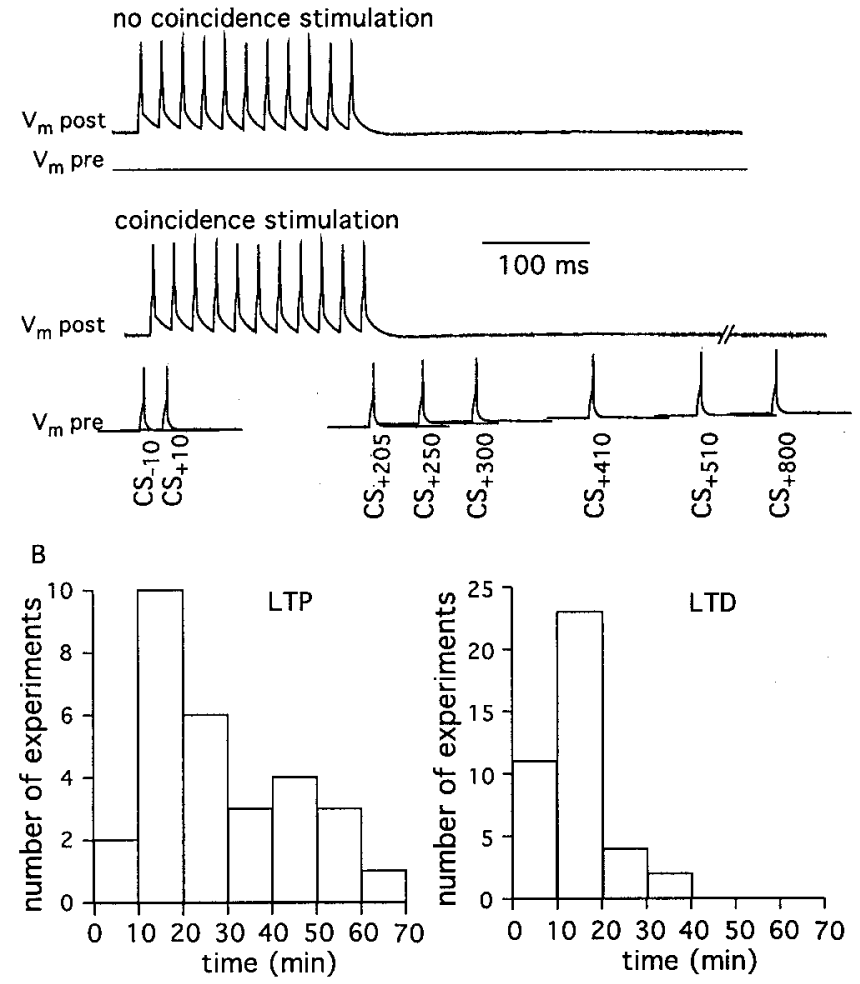

Figure 1. Conditioning protocols used for the induction of synaptic plasticity. $A$, A train of 10 backpropagating APs $(50 \mathrm{~Hz})$ was initiated in a pyramidal cell $\left(V_{m}\right.$ post $)$ by $5 \mathrm{msec}$ current injections in the soma, and an AP was initiated in an FSN neuron $\left(V_{m}\right.$ pre $)$ at different times relative to the beginning of the AP train. $B$, Time distributions of synaptic plasticity observation after conditioning application in different experiments.

midal) cells was in the range of 40-80 M $\Omega$ and was thoroughly controlled throughout the experiment. Resting membrane potential of pyramidal cells was $74 \pm 1.2 \mathrm{mV}(n=22)$ and was stable during the experiment in most cases. Small variations in the cell resting potential (a few millivolts) were corrected by a current injection into a soma when necessary.

Five neuron pairs were morphologically reconstructed with the aid of computerized camera Lucida system. Neurons were filled during experiments with $2 \mathrm{mg} / \mathrm{ml}$ neurobiotin.

Conditioning protocols used for the induction of long-term changes in synaptic efficacy of inhibitory transmission between FSN and pyramidal cells were as follows (Fig. $1 A$ ). The conditioning train of 10 backpropagating dendritic APs was initiated by $5 \mathrm{msec}$ current injections in the soma of pyramidal cell at $50 \mathrm{~Hz}$. In the FSN neuron, an AP was initiated at different times relative to the beginning of the AP conditioning train in the pyramidal cell. This time is given as a subscript to the headers of the coincidence stimulation (CS) in Figure $1 A$. The pattern of sequential postsynaptic and presynaptic stimulation was repeated every $5-7 \mathrm{sec}$ for 25-40 times.

Figure $1 B$ shows time distributions of observation of changes in synaptic efficacy after conditioning application in different experiments. In a relatively small number of experiments with IPSP depression, the observation time exceeded $20 \mathrm{~min}$. However, because recovery of IPSPs from depression was never observed in our experiments, we will further refer to this process as LTD.

In control and after conditioning, the paired-pulse stimulation (100 msec interpulse interval, each $7 \mathrm{sec}$ ) was applied in most experiments to evaluate the paired-pulse depression. For other data analysis, only the first IPSP during such stimulation was used. A paired-pulse ratio (PPR) was calculated as IPSP2/IPSP1, in which IPSP1 and IPSP2 were average IPSP amplitudes in response to the first and second APs, respectively. The mean amplitude of unitary IPSPs was measured from $50-100$ sweeps.

IPSPs were counted as potentiated or depressed if their amplitudes measured in control were significantly different to those measured after conditioning (unpaired Student's $t$ test). The minimum change in the mean IPSP amplitude consistent with this test was $8 \%$. The absence of a tendency of IPSP amplitudes to increase or decrease in control over time was also verified by the unpaired Student's $t$ test.

In $\sim 30 \%$ of all experiments, a rundown of IPSPs was observed. The rundown usually started soon (1-3 min) after obtaining the whole-cell configuration. It was indicated by a gradual decrease in the amplitude of IPSPs and was not associated with a change in the cell resting potential. These experiments were not analyzed further.

Average data are given as mean \pm SEM. Statistical significance of difference in mean IPSPs was analyzed by paired Student's $t$ test.

\section{RESULTS}

\section{LTP and LTD of inhibitory transmission}

Conditioning by the $\mathrm{CS}_{+410}$ and $\mathrm{CS}_{+510}$ protocols in most cell pairs induced LTP of IPSPs. Figure $2 A$ demonstrates one experiment in which considerable IPSP potentiation was evoked by the $\mathrm{CS}_{+410}$ conditioning. The IPSP potentiation lasted for $\sim 1 \mathrm{hr}$ until termination of the experiment. Horizontal lines indicate the amplitudes of mean IPSPs. These mean IPSPs are also shown in the top panel. In 34 cell pairs tested in similar experiments, LTP of inhibitory transmission ranging from 108 to $261 \%$ of control was observed after conditioning. The mean IPSP amplitude was $160 \pm 16 \%$ of control after $\mathrm{CS}_{+410}(n=10 ;$ mean $\pm \mathrm{SEM} ; p<$ $0.01)$ and $142 \pm 6 \%$ of control after $\operatorname{CS}_{+510}(n=24 ; p<0.01)$.

Surprisingly, a shorter delay between the train of backpropagating APs and synaptic stimulation resulted in LTD of IPSPs. Figure $2 B$ demonstrates one experiment in which conditioning by $\mathrm{CS}_{+250}$ induced a prominent long-lasting decrease of IPSPs. Horizontal lines indicate the amplitudes of mean IPSPs, which are also shown in the top panel. Synaptic depression was observed in all five cell pairs after $\mathrm{CS}_{+10}$, and the average IPSP amplitude was $75 \pm 6 \%$ of control $(p<0.01)$. In 9 from 15 cell pairs after $\mathrm{CS}_{+205}(n=15 ; p<0.01)$, the average IPSP amplitude during depression was $69 \pm 0.05 \%$ of control. In all eight cell pairs tested after $\mathrm{CS}_{+250}(p<0.01)$, the average IPSP amplitude was $58 \pm$ $0.06 \%$ of control. Conditioning by $\mathrm{CS}_{-10}, \mathrm{CS}_{+300}$, and $\mathrm{CS}_{+800}$ did not evoke significant changes in IPSPs $(n=8, p>0.4 ; n=9$, $p>0.2$; and $n=5, p>0.8$, respectively). A summary of changes in the efficacy of inhibitory synaptic transmission induced by different conditioning protocols is shown in Figure $2 C$. Figure $2 D$ illustrates variations in synaptic efficacy of inhibitory transmission depending on timing between the conditioning AP train and synaptic stimulation.

To reveal the time course of LTD and LTP development, we averaged IPSPs in all cell pairs in control and after corresponding conditioning protocols $\left(\mathrm{CS}_{+10}, \mathrm{CS}_{+205}, \mathrm{CS}_{+250}\right.$ and $\mathrm{CS}_{+410}$, $\mathrm{CS}_{+510}$, respectively). In each experiment, IPSPs were normalized to the mean IPSP amplitude in control. Then IPSPs in all cell pairs, recorded at equivalent times during the experiment protocol, were averaged. The resulting time courses of LTP and LTD of IPSPs are shown in Figure 2, $E$ and $F$, respectively. Filled circles demonstrate IPSPs averaged within each minute of the experimental protocol. LTP is evident immediately after termination of conditioning, although it continues to increase over the following several minutes. LTD, however, appears to be on a steady-state level after conditioning termination.

\section{LTP and LTD are triggered by an increase in dendritic $\mathbf{C a}^{2+}$}

Because conditioning trains of backpropagating APs induced $\mathrm{Ca}^{2+}$ transients in dendrites (Isomura et al., 1999; Zilberter, 

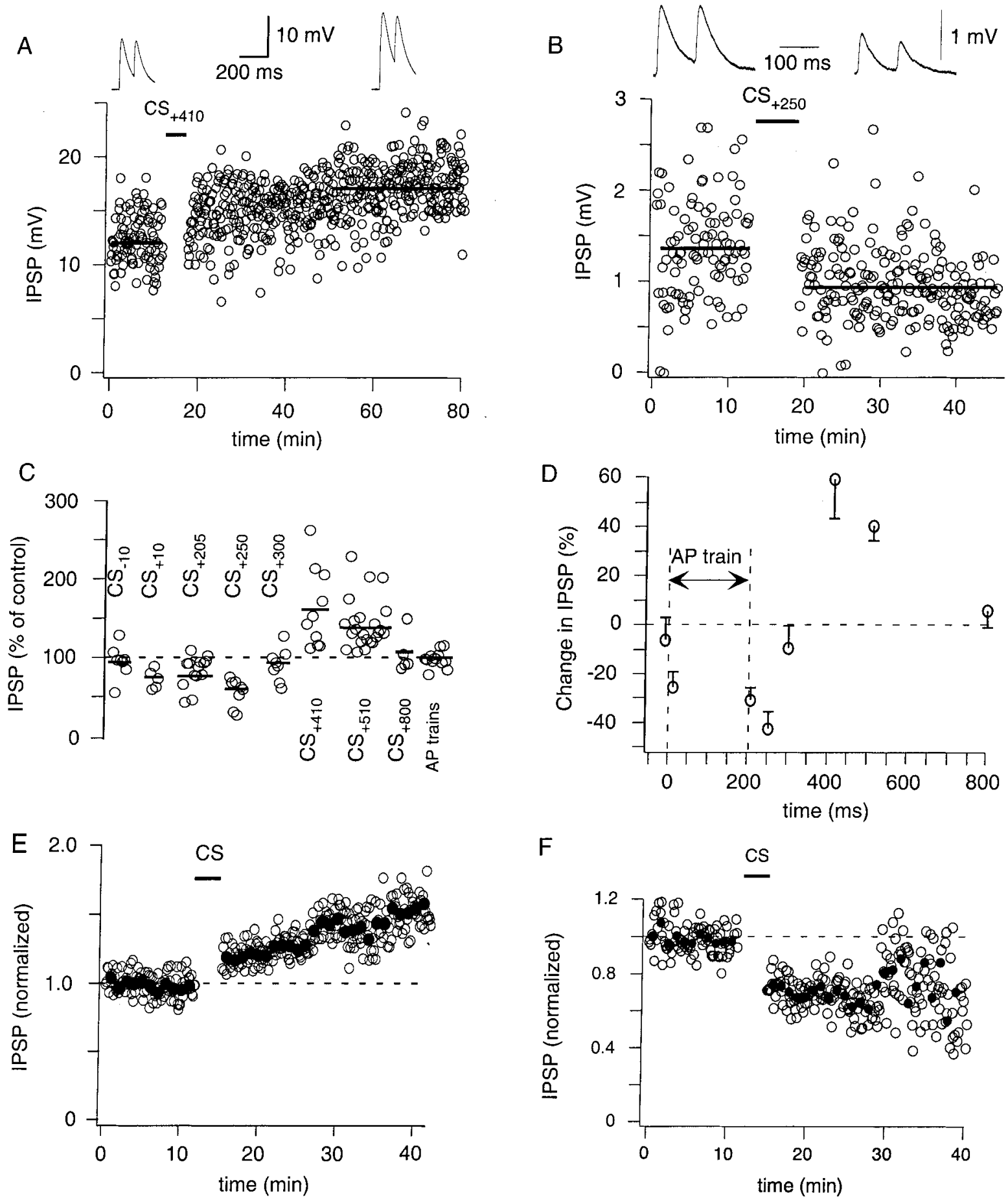

Figure 2. LTP and LTD of inhibitory transmission in pyramidal cells. $A$, LTP of inhibitory transmission between FSN and pyramidal neurons. The mean IPSPs in control and after the $\mathrm{CS}_{+410}$ conditioning are shown in the top panel, and their amplitudes are indicated by horizontal lines in the bottom panel. $B$, LTD of inhibitory transmission. The mean IPSPs in control and after the $\mathrm{CS}_{+250}$ conditioning are shown in the top panel, and their amplitudes are indicated by horizontal lines in the bottom panel. C, Summary of changes in efficacy of inhibitory synaptic transmission in different experiments. Horizontal lines show the mean values. $D$, Variations in efficacy of inhibitory transmission (percentage of control) depending on timing between the conditioning AP train and synaptic stimulation. $E$, IPSPs averaged in 34 cell pairs in control and after conditioning-inducing $\mathrm{LTP}_{(\mathrm{CS}}\left(\mathrm{S}_{+410}\right.$ and $\left.\mathrm{CS}+510\right)$. In each experiment, IPSPs were normalized to the mean IPSP amplitude in control. Then, IPSPs in all cell pairs recorded at equivalent times during the experiment protocol were averaged. Filled circles show IPSPs averaged within each minute of the experimental protocol. $F$, IPSPs averaged in 22 cell pairs in control and after conditioning-inducing $\operatorname{LTD}\left(\mathrm{CS}_{+10}, \mathrm{CS}_{+205}\right.$, and $\left.\mathrm{CS}_{+250}\right)$ by the same procedure as in Figure $1 E$.

2000; Kaiser et al., 2001) and spines (Majewska et al., 2000) of $\mathrm{L} 2 / 3$ pyramidal cells, an increase in dendritic $\left[\mathrm{Ca}^{2+}\right]_{i}$ was suggested to be a trigger of synaptic plasticity. Indeed, in six cell pairs, $5 \mathrm{~mm}$ BAPTA loaded into pyramidal cells via the pipette solution prevented induction of LTP after the $\mathrm{CS}_{+410}$ conditioning protocol. The mean IPSP was $1.78 \pm 0.12 \mathrm{mV}$ in control and $1.72 \pm 0.11 \mathrm{mV}$ after $\mathrm{CS}_{+410}$ in the presence of BAPTA $(p>$ $0.4)$. Interestingly, EGTA $(5 \mathrm{~mm})$, which has the same $\mathrm{Ca}^{2+}$ 
A
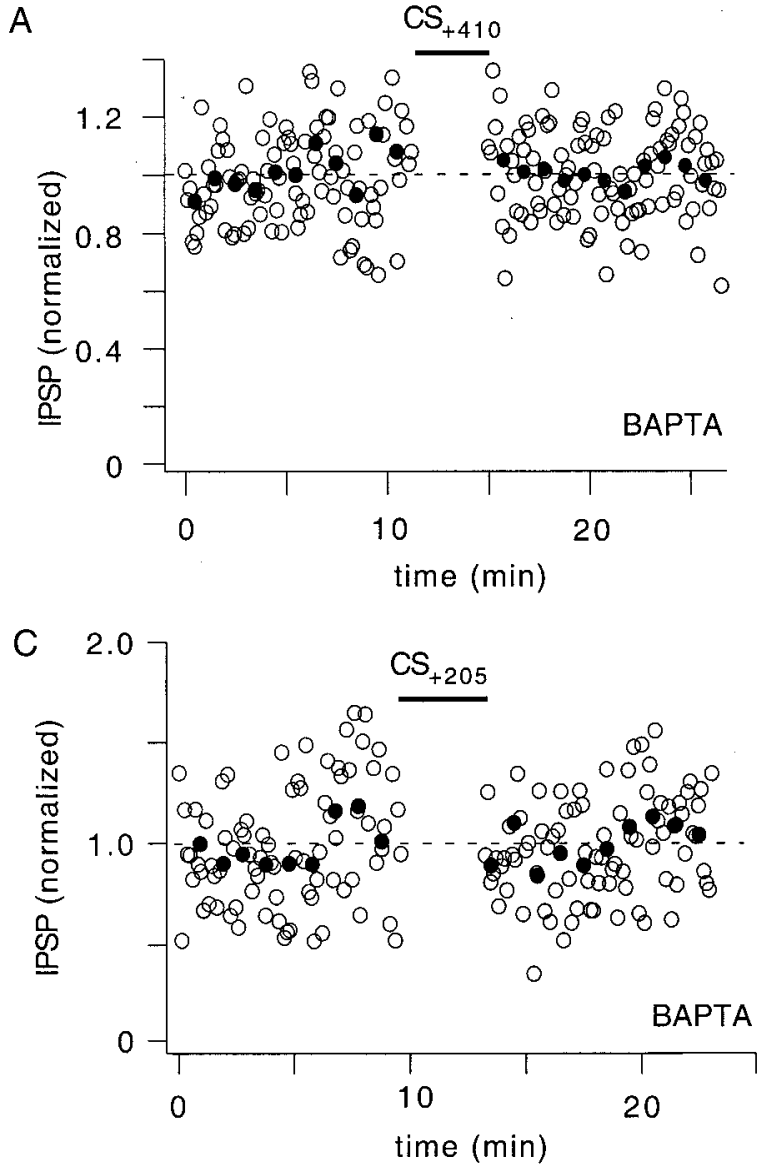
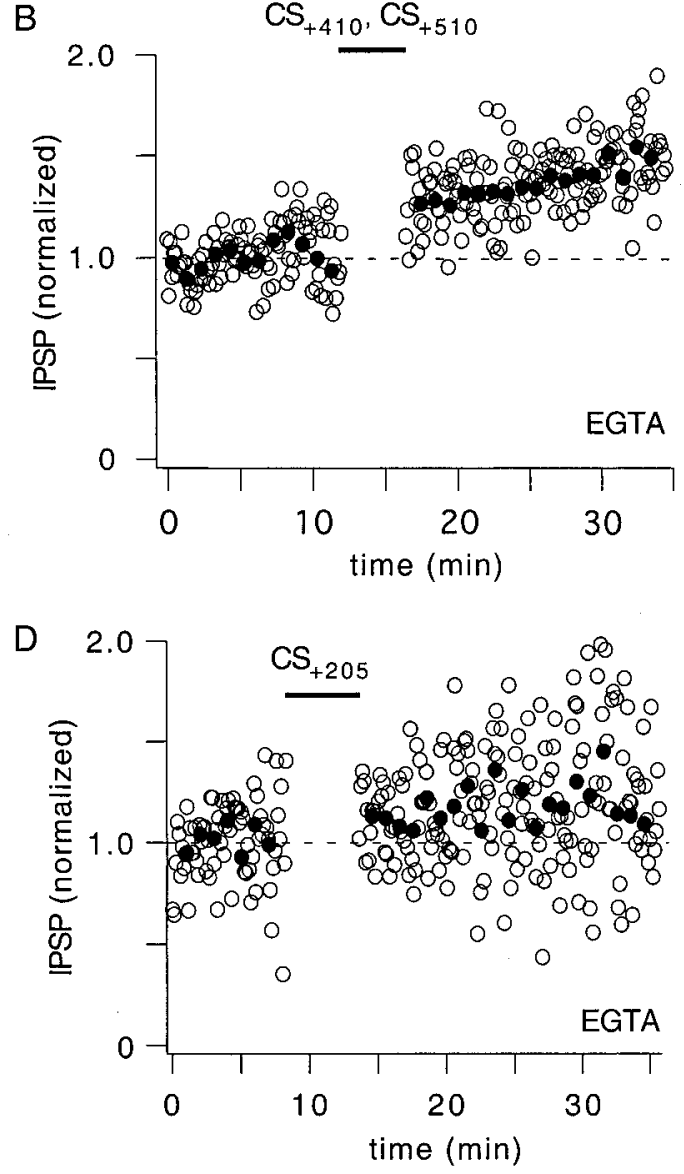

Figure 3. Induction of LTP and LTD of inhibitory transmission is $\mathrm{Ca}^{2+}$ dependent. $A$, Averaged in six cell pairs, IPSPs measured in control and after the $\mathrm{CS}_{+410}$ conditioning with $5 \mathrm{~mm}$ BAPTA loaded into pyramidal cells. BAPTA prevented the LTP induction. $B$, Averaged in seven cell pairs, IPSPs measured in control and after the $\mathrm{CS}_{+410}(n=3)$ and $\mathrm{CS}_{+510}(n=4)$ conditioning with $5 \mathrm{~mm}$ EGTA loaded into pyramidal cells. EGTA did not affect the LTP induction. $C$, Averaged in four cell pairs, IPSPs measured in control and after the $C_{+205}$ conditioning with 5 mM BAPTA loaded into pyramidal

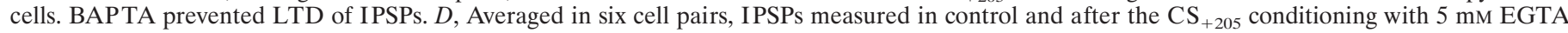
loaded into pyramidal cells. EGTA prevented LTD of IPSPs. Note LTP of IPSPs unmasked with the presence of EGTA . In all figures, IPSPs were averaged by the same procedure as in Figure $1 E$.

buffer capacity as BAPTA but much slower binding kinetics, failed to affect the LTP induction. In seven cell pairs, IPSP potentiation to $156 \pm 14 \%$ of control was observed after $\mathrm{CS}_{+410}$ $(n=3)$ and $\mathrm{CS}_{+510}(n=4)$ protocols in the presence of EGTA $(p<0.01)$. Normalized IPSPs averaged in the experiments described above are shown in Figure $3, A$ and $B$.

Meanwhile, both BAPTA and EGTA prevented the LTD initiation (Fig. $3 C, D$ ). In four cell pairs, the mean IPSP was $1.2 \pm 0.5$ $\mathrm{mV}$ in control and $1.17 \pm 0.4 \mathrm{mV}$ after $\mathrm{CS}_{+205}$ in the presence of BAPTA. With similar conditioning, EGTA not only prevented the initiation of LTD but also unmasked the LTP development. LTP of IPSPs was observed in five of six cell pairs tested and was $119 \pm 6 \%$ of control $(n=6 ; p<0.05)$.

These results indicate that an initiating step in the induction of inhibitory transmission LTP is triggered rapidly after $\mathrm{Ca}^{2+}$ influx into dendrites, whereas the LTD initiation is slower. They also suggest that both processes, LTP and LTD of inhibitory transmission, may develop in parallel: LTD predominates at shorter delays between initiation of $\mathrm{Ca}^{2+}$ influx into dendrites and synaptic stimulation, whereas LTP takes over at longer ones.

\section{LTP and LTD are not induced by variations in GABA release probability}

To examine the site of expression of synaptic plasticity, PPR of IPSPs was measured in most experiments. PPR was not changed significantly by any conditioning protocol (Fig. $4 A$ ). One possibility is that the paired-pulse depression may be induced predominantly by desensitization of postsynaptic $\mathrm{GABA}_{\mathrm{A}}$ receptors. However, PPR could be widely modulated by affecting GABA release probability in presynaptic terminals.

As an example, Figure $4 B$ demonstrates the effects of lowered external $\mathrm{Ca}^{2+}$ concentration $(1 \mathrm{~mm})$ and an agonist of metabotropic glutamate receptors (mGluRs), (士)-1-amino-1,3cyclopentanedicarboxylic acid (ACPD) $(100 \mu \mathrm{M})$, on PPR. Both the decrease in $\mathrm{Ca}^{2+}$ concentration and ACPD induced strong inhibition of IPSPs (to $29 \pm 3 \%$ of control, $n=3$; and to $28 \pm 3 \%$ of control, $n=7$, respectively) and converted IPSP paired-pulse depression to IPSP paired-pulse facilitation.

Stability of PPR after induction of LTD or LTP of IPSPs suggests a lack of transmitter release probability contribution to these processes. The alternative possibility of presynaptic expres- 
A

Figure 4. GABA release probability and reversal potential of synaptic currents are not changed during LTP or LTD. $A$, A summary of PPR measured in different experiments. $B$, Change in PPR induced by lowering the extracellular $\mathrm{Ca}^{2+}$ concentration to $1 \mathrm{mM}(n=3)$ and by the antagonist of mGluRs, ACPD (100 $\mu \mathrm{M} ; n=7)$. $C$, Current-voltage relationships of synaptic currents in control (open circles) and after conditioning (filled circles) by $\mathrm{CS}_{+205}(n=3)$ and $\mathrm{CS}_{+410}(n=3)$ protocols. Deviations are shown upward for control and downward for data after conditioning. Dashed vertical lines indicate the $\mathrm{Cl}^{-}$reversal potential, $-48.6 \mathrm{mV}$.
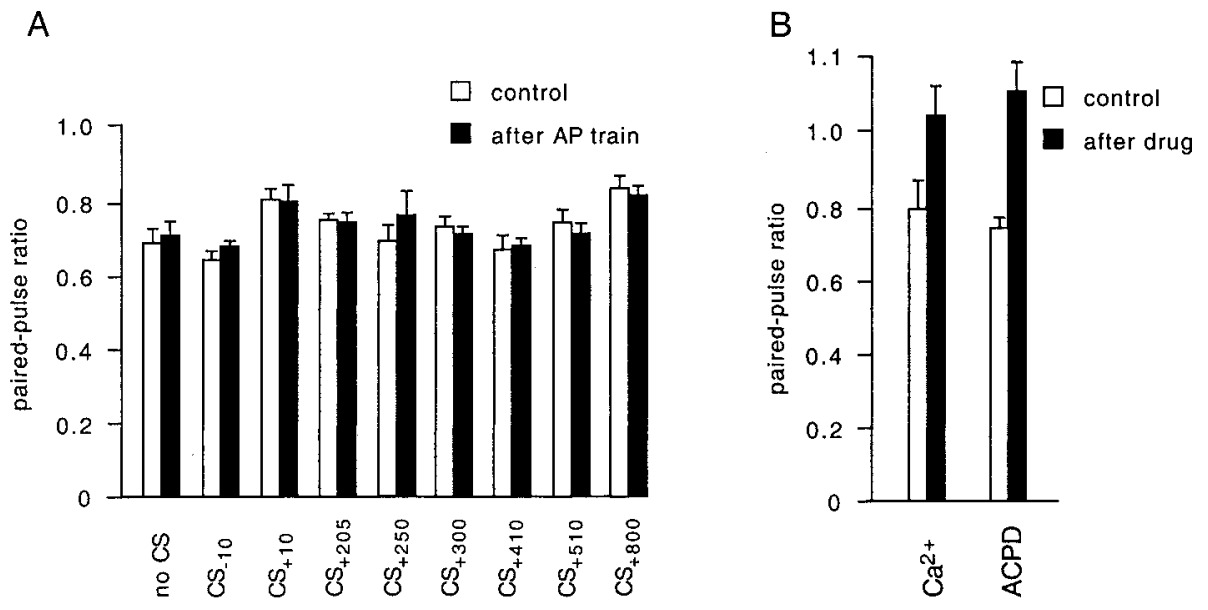

C
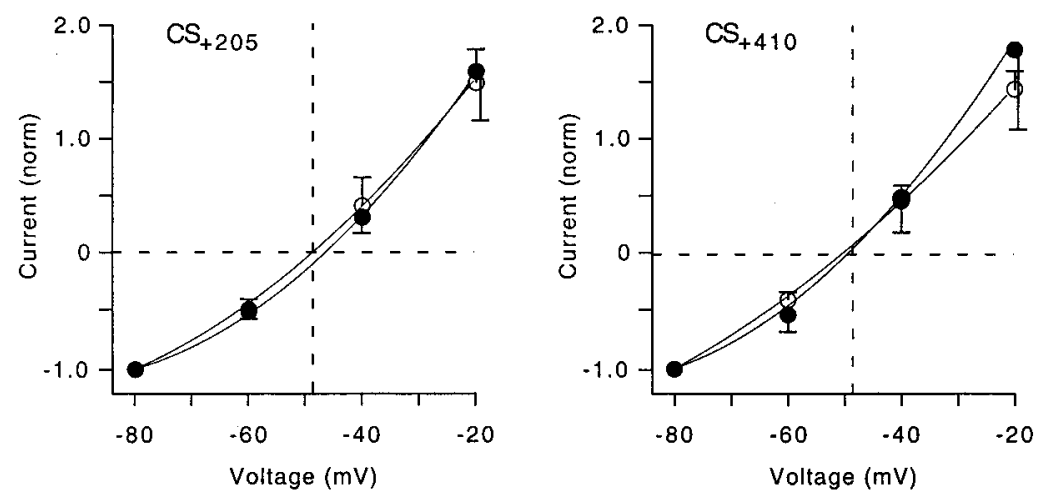

sion of synaptic plasticity, that is, a change in AP propagation to the presynaptic terminals, seems to be unlikely because LTP and LTD of IPSPs may develop in parallel (see above). These results suggest a postsynaptic mechanism of development of synaptic plasticity.

\section{Reversal potential of synaptic currents is not changed by conditioning}

Ganguly et al. (2001) reported recently that the reversal potential of GABA-induced synaptic currents may undergo significant variations during hippocampal cell development in culture. Such synaptic plasticity would result in corresponding change in IPSP amplitudes at the same cell resting potential. In our case, however, the reversal potential of synaptic currents was stable before and after conditioning application (Fig. 4C), indicating a different mechanism of plasticity in inhibitory synapses.

\section{Synaptic activation is required for the induction of synaptic plasticity}

Conditioning by the trains of backpropagating APs without synaptic stimulation did not affect synaptic transmission; in 14 cell pairs, the mean IPSP amplitude was $4.12 \pm 0.97 \mathrm{mV}$ in control and $4.12 \pm 0.95 \mathrm{mV}$ after conditioning $(p>0.4)$. This implies that synaptic activation is necessary for the induction of synaptic plasticity. If synaptic plasticity is expressed postsynaptically, GABA released from the interneuron axon terminals can activate either $\mathrm{GABA}_{\mathrm{A}}$ or $\mathrm{GABA}_{\mathrm{B}}$ postsynaptic receptors. It was reported previously (Komatsu, 1996) that, in the visual cortex L5, LTP of inhibitory transmission induced by a high-frequency stimulation of afferent fibers requires activation of postsynaptic $\mathrm{GABA}_{\mathrm{B}}$ receptors for its induction.
In the present experiments, however, LTP and LTD of unitary IPSPs were initiated in the presence of GDP- $\beta$-S $(0.6 \mathrm{mM})$, preventing $\mathrm{G}$-protein activation, or under a block of $\mathrm{GABA}_{\mathrm{B}}$ receptors by a selective antagonist, $(2 S)-3-\{[(15)-1-(3,4-$ dich-lorophenyl) ethyl]amino-2-hydroxypropyl)(phenylmethyl)phosphinic acid CGP55845A $(2 \mu \mathrm{M})$. In three cell pairs, the mean IPSP amplitude was $148 \pm 32 \%$ of control after $\mathrm{CS}_{+510}$ in the presence of CGP55845A. Induction of LTP was also not affected by GDP- $\beta$-S (0.6 mM) loaded into pyramidal neurons (see below). In two cell pairs, synaptic depression to 65 and $62 \%$ of control was obtained after $\mathrm{CS}_{+250}$ in the presence of GDP- $\beta$-S. Presumably, in L2/3 pyramidal cells, activation of $\mathrm{GABA}_{\mathrm{A}}$ receptors is essential for the induction of long-term plasticity of inhibitory transmission. We tried to obtain direct evidence in favor of this hypothesis by applying conditioning under a block of $\mathrm{GABA}_{\mathrm{A}}$ receptors with a selective antagonist, bicuculline (Komatsu, 1996; Ouardouz and Sastry, 2000). Unfortunately, in three experiments, no IPSP recovery was observed even after $30 \mathrm{~min}$ of bicuculline washout.

\section{Induction of LTP and exocytosis}

Recent studies of excitatory transmission LTP imply a delivery of AMPA receptors to the active synapses by dendritic exocytosis as a possible mechanism of potentiation (Lledo et al., 1998; Lüscher et al., 1999). In these studies, the antagonist of vesicular exocytosis, botulinum toxin B (BoTx-B), prevented LTP induction (Lledo et al., 1998) and AMPA receptor cycling (Lüscher et al., 1999) in CA1 pyramidal cells. The existence of exocytotic machinery in the dendrites of neocortical L2/3 pyramidal cells was also suggested in a previous study (Zilberter, 2000) because dendritic $\mathrm{Ca}^{2+}$-dependent release of a retrograde messenger was 

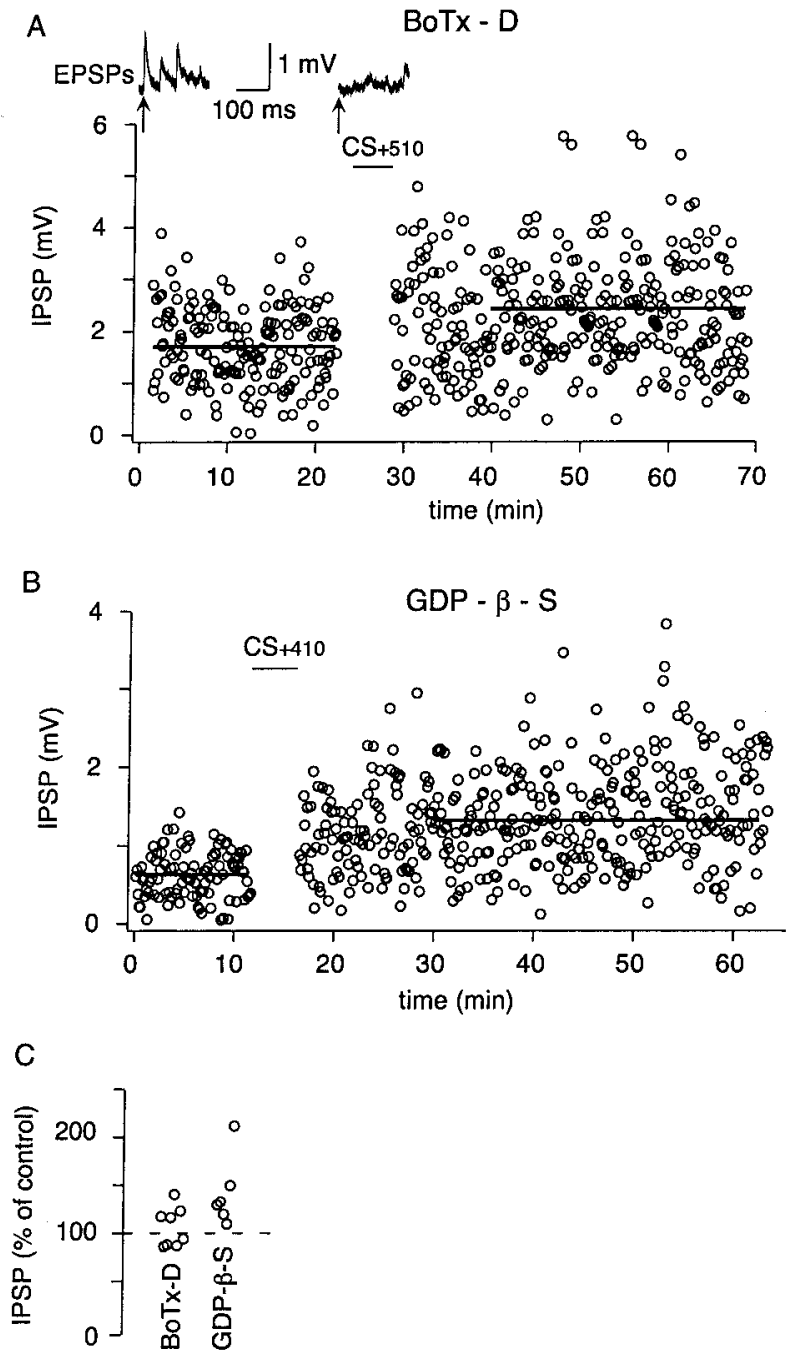

Figure 5. Antagonists of exocytosis do not affect the induction of LTP. $A$, LTP of IPSPs induced by $\mathrm{CS}_{+510}$ at $400 \mu \mathrm{M}$ BoTx-D (light chain) loaded into the pyramidal cell. Horizontal lines indicate the amplitudes of mean IPSPs. The FSN and pyramidal cells were reciprocally connected, and the top panel shows EPSPs measured in the FSN neuron in the beginning of recordings, which disappeared before conditioning (arrows indicate the time of EPSP recordings). B, LTP of IPSPs induced by $\mathrm{CS}_{+410}$ at $0.6 \mathrm{~mm}$ GDP- $\beta$-S loaded into the pyramidal cell. Horizontal lines indicate the amplitudes of mean IPSPs. $C$, A summary of experiments with BoTx-D and GDP- $\beta$-S.

prevented by the antagonists of vesicular exocytosis BoTx-D (Xu et al., 1998; Schiavo et al., 2000) and GDP- $\beta$-S (Hess et al., 1993; Zilberter et al., 1999; Zilberter, 2000). However, neither BoTx-D nor GDP- $\beta$-S affected the induction of inhibitory transmission LTP in this study. Figure $5 A$ shows one experiment in which the pyramidal cell was loaded with the BoTx-D light chain (400 nM) added to the pipette solution. The pyramidal and FSN cells were reciprocally connected, and EPSPs in the FSN neuron were recorded periodically to verify the diffusion of BoTx-D to the presynaptic sites (see the top panel), suggesting therefore that the toxin had already diffused to the dendrites. EPSPs disappeared 22 min after the beginning of recordings, and $\mathrm{CS}_{+510}$ was applied thereafter, resulting in a pronounced LTP of IPSPs. LTP was observed in four $(125 \pm 6 \%$ of control) of eight similar experiments. A lack of the effect of conditioning in half of the experiments can be explained by a prolonged waiting time before conditioning application (up to $50 \mathrm{~min}$ ), justified by the slow diffusion of BoTx-D light chain attributable to its high molecular weight $(50 \mathrm{kDa})$. Presumably, some important intracellular ingredients were washed out during this period. It is also necessary to note that BoTx-D cannot be considered as a selective antagonist of vesicular exocytosis in neocortical cells because it strongly affected dendritic $\mathrm{Ca}^{2+}$ signaling in both $\mathrm{L} 2 / 3$ pyramidal cells (Zilberter, 2000) and interneurons (Zilberter et al., 1999).

As an alternative way of inhibiting exocytosis, we used $0.6 \mathrm{~mm}$ GDP- $\beta$-S loaded into pyramidal cells (Hess et al., 1993; Zilberter et al., 1999; Zilberter, 2000). Because GDP- $\beta$-S is a considerably smaller molecule than the BoTx-D light chain, it diffused much faster to the inhibitory synapses on the pyramidal cell dendrites (five reconstructed cell pairs; $117 \pm 13 \mu \mathrm{m}$ from the soma; $n=$ 20). Tested in six cell pairs, GDP- $\beta$-S loaded into pyramidal cells inhibited EPSPs measured in interneurons to $14 \pm 6 \%$ of control during 9-15 min after establishing the whole-cell configuration. In experiments with GDP- $\beta$-S, LTP was observed in all cell pairs $\left(n=6 ; 143 \pm 15 \%\right.$ of control; $\left.\mathrm{CS}_{+410}, n=3 ; \mathrm{CS}_{+510}, n=3\right)$. Figure $5 B$ demonstrates one of these experiments. Summary of all experiments with BoTx-D and GDP- $\beta-S$ is shown in Figure $5 C$. These results, together with a lack of EGTA effect on the LTP induction (see Discussion), oppose the idea that dendritic exocytosis is involved in the mechanism of LTP in inhibitory synapses between FSN and pyramidal cells.

\section{DISCUSSION}

Although the long-term modulation of excitatory transmission was intensively studied during the last decades, much less attention has been paid to the inhibitory transmission. However, a lack of corresponding information on the role of inhibitory interneurons and their contribution to the regulation of synaptic plasticity underlies the general problem of understanding the role of LTP in the learning process (Paulsen and Sejnowski, 2000).

Both LTP (Morishita and Sastry, 1991; Kano et al., 1992; Komatsu and Iwakiri, 1993; Komatsu, 1994; McLean et al., 1996; Aizenman et al., 1998; Shew et al., 2000) and LTD (Komatsu and Iwakiri, 1993; McLean et al., 1996; Morishita and Sastry, 1996; Aizenman et al., 1998) of inhibitory transmission in different mammalian brain regions have been reported. Despite the limited number of these papers, a variety of mechanisms have been proposed for the induction of synaptic plasticity. In all of these studies, synaptic responses were evoked by stimulation of afferent fibers. With a high-frequency stimulation, LTD of inhibitory transmission was observed in CA3 pyramidal cells (McLean et al., 1996) and in L5 of visual cortex (Komatsu and Iwakiri, 1993), although LTP occurred when NMDA receptors were blocked. Afferent tetanization induced LTP of IPSCs in deep cerebellar nuclei (DCN) neurons (Ouardouz and Sastry, 2000), whereas a 10 $\mathrm{Hz}$ stimulation initiated LTD (Morishita and Sastry, 1996). A unique property of DCN cells is a prominent rebound depolarization and associated spike bursting after the IPSP-induced membrane hyperpolarization. Depending on the number of spikes during the rebound depolarization and on the corresponding $\mathrm{Ca}^{2+}$ influx into a postsynaptic DCN cell, either LTD or LTP of IPSPs could be initiated (Aizenman et al., 1998).

The present study demonstrates that AP generation in presynaptic and postsynaptic neurons, correlated in time, may induce long-term plasticity of synaptic efficacy in inhibitory contacts. The polarity of these variations in synaptic efficacy depends on timing between spike generation in a pyramidal cell and FSN interneuron. Both LTP and LTD of inhibitory transmission are triggered 
by an increase in postsynaptic dendritic $\mathrm{Ca}^{2+}$ concentration induced by backpropagating APs in the pyramidal cell but also require GABAergic synapse activation for their induction.

In most studies available on long-term plasticity of inhibitory synaptic transmission, LTP and LTD were also initiated by an increase in postsynaptic $\left[\mathrm{Ca}^{2+}\right]_{\mathrm{i}}$ (Kano et al., 1992; Komatsu and Iwakiri, 1993; Komatsu, 1996; McLean et al., 1996; Morishita and Sastry, 1996; Aizenman et al., 1998; Caillard et al., 1999; Ouardouz and Sastry, 2000). Synaptic plasticity could be induced solely by the postsynaptic membrane depolarization and subsequent $\mathrm{Ca}^{2+}$ influx (Llano et al., 1991; McLean et al., 1996; Morishita and Sastry, 1996; Aizenman et al., 1998; Caillard et al., 1999; Ouardouz and Sastry, 2000). Moreover, transition between LTD and LTP was suggested to be directly dependent on the level of increase in $\left[\mathrm{Ca}^{2+}\right]_{\mathrm{i}}$ (Aizenman et al., 1998; Ouardouz and Sastry, 2000).

In our study, postsynaptic membrane depolarization with a corresponding $\mathrm{Ca}^{2+}$ influx mediated by backpropagating APs (Zilberter, 2000; Kaiser et al., 2001) failed to affect the efficacy of inhibitory transmission unless accompanied by the activation of inhibitory synapses. It is unlikely that polarity of synaptic plasticity (LTD or LTP) during coincidence of the increase in dendritic $\left[\mathrm{Ca}^{2+}\right]_{\mathrm{i}}$ and synaptic activation was determined by the level of $\left[\mathrm{Ca}^{2+}\right]_{\mathrm{i}}$ for the following reasons. The time constant of $\mathrm{Ca}^{2+}$ transient decay in the pyramidal cell dendrites is $\sim 150 \mathrm{msec}$ on average (Kaiser et al., 2001); thus, the $\left[\mathrm{Ca}^{2+}\right]_{\mathrm{i}}$ level is much higher during synaptic stimulation inducing LTD of IPSPs $\left(\mathrm{CS}_{+10}, \mathrm{CS}_{+205}\right.$, and $\left.\mathrm{CS}_{+250}\right)$. However, LTP of IPSPs was not prevented by EGTA, in contrast to LTD. This indicates that (1) after elevation of $\left[\mathrm{Ca}^{2+}\right]_{i}$, the LTP process is initiated faster than the LTD one, and (2) the level of $\left[\mathrm{Ca}^{2+}\right]_{i}$ at the moment of synaptic stimulation is not significant for the development of synaptic plasticity. Besides, eliminating the LTD initiation in the presence of EGTA (Fig. 3D) unmasked LTP of IPSPs induced by the same conditioning $\left(\mathrm{CS}_{+205}\right)$. This suggests that both processes, LTD and LTD of IPSPs, may coexist, developing in parallel.

What may be a mechanism of plasticity in inhibitory synapses? Although the present study does not answer this question, it suggests that the dendritic exocytotic machinery is most likely not involved in this process. First, the antagonists of vesicular exocytosis, BoTx-D (Xu et al., 1998; Schiavo et al., 2000) and GDP- $\beta$-S (Hess et al., 1993; Zilberter et al., 1999; Zilberter, 2000), did not prevent development of IPSP LTP. Note, however, that neither GDP- $\beta$-S nor BoTx-D are selective inhibitors of exocytosis and thus cannot provide the direct evidence against its involvement in LTP. In neocortical bitufted interneurons (Reyes et al., 1998), BoTx-D decreased the amplitude of dendritic $\mathrm{Ca}^{2+}$ transients to $66 \%$ of control (Zilberter et al., 1999), although it increased $\mathrm{Ca}^{2+}$ transients to $182 \%$ of control in dendrites of $\mathrm{L} 2 / 3$ pyramidal cells (Zilberter, 2000).

Second, the lack of EGTA effect on the development of LTP favors our suggestion. EGTA inhibited exocytosis in endocrine cells (Neher and Marty, 1982), dorsal root ganglion neuron somata (Huang and Neher, 1996), and dendrites of cultured hippocampal neurons (Maletic-Savatic and Malinow, 1998). In CNS nerve terminals, EGTA also inhibited evoked release, although less effectively than BAPTA (Borst and Sakmann, 1996; Ohana and Sakmann, 1998; Rozov et al., 2001).

As a possible mechanism of synaptic plasticity, we hypothesize the upregulation or downregulation of the active conformation of $\mathrm{GABA}_{\mathrm{A}}$ receptors by their phosphorylation by $\mathrm{Ca}^{2+}$-dependent protein kinase(s) (Kano et al., 1996) or dephosphorylation by protein phosphatases(s) (Morishita and Sastry, 1996). This assumption, however, should be tested in future experiments.

Pyramidal cells and FSN interneurons are reciprocally connected in most cases (Zilberter, 2000). This type of synaptic connectivity was also found between pyramidal cells and bitufted interneurons in L2/3 of neocortex (Reyes et al., 1998; Zilberter et al., 1999), as well as between pyramidal cells and multipolar interneurons in L2/3 (Reyes et al., 1998) (see also Buhl et al., 1997), suggesting that such microcircuits represent a general case in neocortex. Both excitatory and inhibitory connections in a microcircuit consisting of the pyramidal and FSN cells are usually reliable and efficient. This is indicated by a negligible probability of synaptic failures during EPSP or IPSP recordings and by the normally big amplitude of EPSPs and IPSPs. Thus, both the FSN interneuron and pyramidal cell in the microcircuit can effectively control excitability of each other. Namely, variations in the efficacy of inhibitory transmission may modulate the temporal pattern of APs in the output of pyramidal cell.

Let us assume, for example, that during a hypothetical learning episode a temporal pattern of APs is repeatedly generated in the axonal output of the pyramidal cell. These APs may initiate LTP of the corresponding excitatory transmission because the APs will also propagate back to the dendrites reaching the excitatory synapses with some delay (in the order of a millisecond) with respect to the initiating EPSPs (Magee and Johnston, 1997; Markram et al., 1997a; Bi and Poo, 1998; Debanne et al., 1998; Egger et al., 1999). LTP of excitatory transmission onto the pyramidal cell, on the other hand, would also induce an increased backward inhibition by the interneuron. However, the mechanisms of synaptic plasticity in inhibitory synapses onto the pyramidal cell limit its suppression by the interneuron. First, the efficacy of inhibitory synapses onto the pyramidal cell will undergo a short-term depression during backpropagating AP trains attributable to the $\mathrm{Ca}^{2+}$-dependent dendritic release of a retrograde messenger (Zilberter et al., 1999; Zilberter, 2000). Second, the repeated pattern of backpropagating APs in the pyramidal cell will induce LTD of IPSPs in the temporal vicinity of the pattern, thus creating a long-lasting favorable background for the pattern generation. Finally, the same repeated AP pattern will induce LTP of more temporally distant IPSPs causing increased inhibition of pyramidal cell spikes asynchronous with the pattern. Thus, the AP patterns formed during learning episodes are defined by several mechanisms of synaptic plasticity in this elementary neuronal microcircuit.

\section{REFERENCES}

Aizenman CD, Manis PB, Linden DJ (1998) Polarity of long-term synaptic gain change is related to postsynaptic spike firing at a cerebellar inhibitory synapse. Neuron 21:827-835.

Bi G, Poo M (1998) Synaptic modifications in cultured hippocampal neurons: dependence on spike timing, synaptic strength, and postsynaptic cell type. J Neurosci 18:10464-10472.

Borst JG, Sakmann B (1996) Calcium influx and transmitter release in a fast CNS synapse. Nature 383:431-434.

Buhl EH, Tamas G, Szilagyi T, Stricker C, Paulsen O, Somogyi P (1997) Effect, number and location of synapses made by single pyramidal cells onto aspiny interneurons of cat visual cortex. J Physiol (Lond) 500:689-713.

Buzsaki G, Penttonen M, Nadasdy Z, Bragin A (1996) Pattern and inhibition-dependent invasion of pyramidal cell dendrites by fast spikes in the hippocampus in vivo. Proc Natl Acad Sci USA 93:9921-9925.

Caillard O, Ben-Ari Y, Gaiarsa J-L (1999) Long-term potentiation of GABAergic synaptic transmission in neonatal rat hippocampus. J Physiol (Lond) 518:109-119.

Debanne D, Gähwiler BH, Thompson SM (1998) Long-term synaptic 
plasticity between pairs of individual CA3 pyramidal cells in rat hippocampal slice cultures. J Physiol (Lond) 507:237-247.

Egger V, Feldmeyer D, Sakmann B (1999) Coincidence detection and changes of synaptic efficacy in spiny stellate neurons in rat barrel cortex. Nature Neuroscience 2:1098-1105.

Freund TF, Gulyas AI (1997) Inhibitory control of GABAergic interneurons in the hippocampus. Can J Physiol Pharmacol 75:479-487.

Ganguly K, Schinder AF, Wong ST, Poo M (2001) GABA itself promotes the development switch of neuronal GABAergic responses from excitation to inhibition. Cell 105:521-532.

Hess SD, Doroshenko PA, Augustine GJ (1993) A functional role of GTP-binding proteins in synaptic vesicle cycling. Science 259:1169-1172.

Huang L-Y, Neher E (1996) $\mathrm{Ca}^{2+}$-dependent exocytosis in the somata of dorsal root ganglion neurons. Neuron 17:135-145.

Isomura Y, Yamamoto K, Hashimoto K, Kato N (1999) Postnatal development of action potential-induced dendritic calcium entry in neocortical layer II/III pyramidal cells. Brain Res 832:175-178.

Kaiser KMM, Zilberter Y, Sakmann B (2001) Back-propagating action potentials mediate calcium signalling in dendrites of bitufted interneurons in layer $2 / 3$ of rat somatosensory cortex. J Physiol (Lond) 535:17-31.

Kano M, Rexhausen U, Dressen J, Konnerth A (1992) Synaptic excitation produces a long-lasting rebound potentiation of inhibitory synaptic signals in cerebellar Purkinje cells. Nature 356:601-604.

Kano M, Kano M, Fukunaga K, Konnerth A (1996) $\mathrm{Ca}^{2+}$-induced rebound potentiation of $\gamma$-aminobutyric acid-mediated currents requires activation of $\mathrm{Ca}^{2+} /$ calmodulin-dependent kinase II. Proc Natl Acad Sci USA 93:13351-13356.

King C, Henze DA, Leinekugel X, Buzsaki G (1999) Hebbian modification of a hippocampal population pattern in the rat. J Physiol (Lond) 521:159-167.

Komatsu Y (1994) Age-dependent long-term potentiation of inhibitory synaptic transmission in rat visual cortex. J Neurosci 14:6488-6499.

Komatsu Y (1996) GABA $_{B}$ receptors, monoamine receptors, and postsynaptic inositol triphosphate-induced $\mathrm{Ca}^{2+}$ release are involved in the induction of long-term potentiation at visual cortical inhibitory synapses. J Neurophysiol 16:6342-6352.

Komatsu Y, Iwakiri M (1993) Long-term modification of inhibitory synaptic transmission in developing visual cortex. NeuroReport 4:907-910.

Larkum ME, Zhu JJ, Sakmann B (1999) A new cellular mechanism for coupling inputs arriving at different cortical layers. Nature 398:338-341.

Llano I, Leresche N, Marty A (1991) Calcium entry increases the sensitivity of cerebellar Purkinje cells to applied GABA and decreases inhibitory synaptic currents. Neuron 6:565-574.

Lledo P-M, Zhang X, Südhof TC, Malenka RC, Nicoll RA (1998) Postsynaptic membrane fusion and long-term potentiation. Science 279:399-403.

Lüscher C, Xia H, Beattie EC, Carroll RC, von Zastrow M, Malenka RC, Nicoll RA (1999) Role of AMPA receptor cycling in synaptic transmission and plasticity. Neuron 24:649-658.

Magee JC, Johnston D (1997) A synaptically controlled, associative signal for Hebbian plasticity in hippocampal neurons. Science 275:209-213.

Majewska A, Tashiro A, Yuste R (2000) Regulation of spine calcium dynamics by rapid spine motility. J Neurosci 20:8262-8268.

Maletic-Savatic M, Malinow R (1998) Calcium-evoked dendritic exocy- tosis in cultured hippocampal neurons. I. trans-Golgi network-derived organelles undergo regulated exocytosis. J Neurosci 18:6803-6813.

Markram H, Lübke J, Frotscher M, Sakmann B (1997a) Regulation of synaptic efficacy by coincidence of postsynaptic APs and EPSPs. Science 275:213-215.

Markram H, Lübke J, Frotscher M, Roth A, Sakmann B (1997b) Physiology and anatomy of synaptic $\mathrm{Ca}^{2+}$ thick tufted pyramidal neurones in the developing rat neocortex. J Physiol (Lond) 500:409-440.

McLean HA, Caillard O, Ben-Ari Y, Gaiarsa J-L (1996) Bidirectional plasticity expressed by GABAergic synapses in the neonatal rat hippocampus. J Physiol (Lond) 496 2:471-477.

Miles R, Tóth K, Gulyás AI, Hájos N, Freund TF (1996) Differences between somatic and dendritic inhibition in the hippocampus. Neuron 16:815-823.

Morishita W, Sastry BR (1991) Chelation of postsynaptic $\mathrm{Ca}^{2+}$ facilitates long-term potentiation of hippocampal IPSPs. NeuroReport 2:533-536.

Morishita W, Sastry BR (1996) Post-synaptic mechanisms underlying long-term depression of GABAergic transmission in neurons of the deep cerebellar nuclei. J Neurophysiol 76:59-68.

Neher E, Marty A (1982) Descrete changes in cell membrane capacitance observed under conditions of enhanced secretion in bovine adrenal chromaffin cells. Proc Natl Acad Sci USA 79:6712-6716.

Ohana O, Sakmann B (1998) Transmitter release modulation in nerve terminals of rat neocortical pyramidal cells by intracellular calcium buffers. J Physiol (Lond) 513:135-148.

Ouardouz M, Sastry BR (2000) Mechanisms underlying LTP of inhibitory synaptic transmission in the deep cerebellar nuclei. J Neurophysiol 84:1414-1421.

Paulsen O, Sejnowski TJ (2000) Natural patterns of activity and longterm synaptic plasticity. Curr Opin Neurobiol 10:172-179.

Reyes A, Lujan R, Rozov A, Burnashev N, Somogyi P, Sakmann B (1998) Target cell-specific facilitation and depression in neocortical circuits. Nat Neurosci 1:279-285.

Rozov A, Burnashev N, Sakmann B, Neher E (2001) Transmitter release modulation by intracellular $\mathrm{Ca}^{2+}$ buffers in facilitating and depressing nerve terminals of pyramidal cells in layer $2 / 3$ of the rat neocortex indicates a target cell-specific difference in presynaptic calcium dynamics. J Physiol (Lond) 531:807-826.

Schiavo G, Matteoli M, Montecucco C (2000) Neurotoxins affecting neuroexocytosis. Physiol Rev 80:717-766.

Schiller J, Helmchen F, Sakmann B (1995) Spatial profile of dendritic calcium transients evoked by action potentials in rat neocortical pyramidal neurons. J Physiol (Lond) 487:583-600.

Shew T, Yip S, Sastry BR (2000) Mechanisms involved in tetanusinduced potentiation of fast IPSCs in rat hippocampal CA1 neurons. J Neurophysiol 83:3388-3401.

Thomas MJ, Watabe AM, Moody TD, Makhinson M, O'Dell TJ (1998) Postsynaptic complex spike bursting enables the induction of LTP by theta frequency synaptic stimulation. J Neurosci 18:7118-7126.

Xu T, Bin T, Niemann H, Neher E (1998) Multiple kinetic components of exocytosis distinguished by neurotoxin sensitivity. Nat Neurosci $1: 192-200$.

Zilberter Y (2000) Dendritic release of glutamate suppresses synaptic inhibition of pyramidal neurons in rat neocortex. $\mathrm{J}$ Physiol (Lond) 528:489-496.

Zilberter Y, Kaiser KMM, Sakmann B (1999) Dendritic GABA release depresses excitatory transmission between L 2/3 pyramidal and bitufted neurons in rat neocortex. Neuron 24:979-988. 